1. Salpingostomy.-As the result of a mild inflammation the tubal ostium may be sealed up, without evidence of other gross changes in the tube. An artificial ostium can be formed by making a longitudinal incision in the tube, as near to the ovary as possible, and oversewing the cut edges with fine silk to prevent reunion.

2. Drainage of Pus Tubes. - In cases of pyosalpinx the plan has been tried of laying the tube open from end to end and leaving it open to drain. This is done instead of removing the tubes. From the point of view of pregnancy, the chances can at least be no worse, as the result of drainage, than they were before; theoretically, they may be better. But it remains a question whether a tube that has been a pus sac for some time can ever regain its function. Personally I should not be at all sanguine about it; but only time can determine whether the experiment is sometimes worth trying. It may be found that the result as regards pregnancy is nil, and that the damaged tubes remain a source of danger and ill health. It would be necessary, when laying open tubes for drainage, to make sure that the uterine ostium of the tube was patent.

3. Restoration of an Occluded Utcrine Ostium. - Where the tube is not too badly damaged but its uterine end is impervious, attempts have been made to restore this channel. The method adopted has been to pass a long straight needle, threaded with several strands of catgut, along the tube, through the isthmus, into the uterine cavity, and then across through the isthmus of the opposite side into the other tube. Another plan is to open the fundus of the uterus from the front and pass the strands of catgut from the uterine cavity into the tubes. The wound in the uterus is then closed. These ingenious methods are, of course, experimental; and here, again, time alone will show whether they have any practical value. If only one case of pregnancy followed the operation it would be worth while persevering with the attempts, since the alternative to operation is a hopelessly incurable sterility.

\section{Conservative Surgery of the Dterus.}

Perhaps the first warning that should be uttered in this connexion is against meddlesome surgery of the cervix. It is the fashion in some quarters to amputate the cervix for prolapse and procidentia. No doubt it happens occasionally that amputation is required for elongation of the vaginal portion of the cervix. In prolapse there is an appearance of elongation of this portion, and perhaps some operators have mistaken this for a true hypertrophy, and they have thus been led to do an amputation, with results that can only be regarded as very bad from a conservative point of view.

1. Repair of a Torn Cervix.-This is eminently a conservative and prophylactic measure. A deep bilateral tear of the cervix is unfavourable to conception, partly because it is nearly always associated with "erosion," and this in turn causes a muco-purulent discharge, which is noxious to spermatozoa. If pregnancy does occur it is very liable to end in a miscarriage. Repair of the torn cervix is favourable to pregnancy. It is also a sound prophylactic procedure, because such a cervix is in a highly favourable condition for the development of carcinoma.

2. Uterine Fibroids: Prescrvation of the Utcrus.-There are many cases in which uterine fibroids can be treated by myomectomy instead of hysterectomy. Several factors must be considered when deciding between the two operations; but they may be summarized by saying that myomectomy should always be done when it is surgically possible in a woman of child-bearing age, provided that other conditions are favourable for child-bearing, and that the operation does not leave a battered and useless uterus. After the age of 40 to 45 myomectomy seldom has any practical value. Papers advocating the more frequent performance of myomectomy were read by Mr. Bonney and myself at the meeting of the Obstetrical and Gynaecological Section of the Royal Society of Medicine in October, 1922.

3. Radium in Chronic Metritis.-There are cases of chronic metritis that prove refractory to repeated curetting and to vaccine treatment, and it has been found necessary in the past to do a hysterectomy in order to overcome excessive losses or constant purulent discharge. In a woman under 40 one hesitates to resort to this extreme step, and an alternative plan is now offered by radium. A tube containing $110-115 \mathrm{mg}$. of radium is introduced into the uterus after a slight dilatation and left for twenty to twenty-four hours. Many good results have been reported. The treatment is not devoid of the risk of inducing permanent atrophy of the ovaries, in which case the functional results would be even worse than those following hysterectomy. But even where the ovaries have been affected it has sometimes been found that this result is transient, and menstruation has been renewed after some months, showing that the ovarian activity has been restored. A course of repeated applications of $x$ rays seems to have a more damaging effect upon the ovaries than a single application of radium

4. Preservation of Cervix in Hysterectomy for Benign Con. ditions.-A reference has already been made to this. There are, of course, cases where the condition of the cervix necessitates a total hysterectomy. But I am convinced that when the cervix can safely be left the subtotal hysterectomy is a better operation; and this partly for the reason that the vagina is left unaltered and so is better adapted for the cor-tinuation of married life.

\section{THE AFTER-EFFECTS OF CERTAIN INDUSTRIAL INJURIES, AND THEIR TREATMENT BY X RAYS.*}

REGINALD A. MORRELL, M.R.C.S., L.R.C.P., HONORARY RADIOLOGIST TO THE SHEFFIELD ROYAL HOSPITAL; CLINICAL LECTURER, THE UNIVERSITY OF SHEFFIELD.

Certain forms of industrial injury often result in limita tion of function owing to the formation of an excessive amount of fibrous tissue during the process of repair. Examples of such injuries are those involving the tendons of the wrist or fingers after either primary or secondary suture; extensive lacerated wounds or burns of muscle, and even the less serious condition of teno-synovitis. One has only to recall the usual course of treatment in such cases -namely, a prolonged period of after-treatment in the massage and electrical department-to realize that there is a serious economic factor involved, for during this period the patient is being paid compensation and too often the end-results are not at all satisfactory.

It is apparent; therefore, that any treatment which will shorten this period of convalescence and which may possibly improve the end-results deserves to be widely known and extensively practised. The object of this paper is to urge the claims of radiotherapy in such cases. I venture to assert that the final results of suitable $x$-ray treatment are better and more quickly obtained than by the older and more usual methods of massage, movement, and negative electrolysis, all of which I have practised and have definitely discarded.

Whilst fibrous tissue is necessary for the restoration of function, the formation of such tissue in excess of act!nal requirements leads to that limitation of function which is so of ten a marked feature of these cases. The difficulty would be solved if we could change this scar tissue into a supple vascular tissue which would not interfere with function. This, I believe, is what is done by radiotherapy. I find that it is by no means uncommon for these cases to be discharged within a period of two or three weeks from commencing treatment. The treatment is carried out on three days a week only-in other words, an average of nine attendances of thirty minutes each is the only tax on the man's time. The more recent the injury the more easily will the final result be obtained. But the term " recent" is purely relative. It would be more accurate to say that the less fully organized, the more vascular the tissue, the more satisfactory the results. One case has been selected for a detailed report as it is a typical example of limited function resulting from just such an accident-namely, limitation of movement following on tendon suture and persisting in spite of two months' treatment by massage and movement. It was finally converted into an almost perfect functional result by eight treatments in the $x$-ray department spread over a period of two and a half weeks.

The patient had an extensive cut of the second finger of the left hand extending round the front and side of the proximal interphalangeal joint and severing the flexor tendons. The tendons were sutured and the patient was submitted to after-treatment in the massage department for two months. At the end of this time the condition was as shown in Fig. 1 , the movement being limited and the finger thickened and painful.

*A paper read before the Yorkshire Branch of the British Medical 
At the end of the $x$-ray treatment there was no perceptible thickening, movement was free from pain, and there was a complete range of passive movement although
was a few degrees short of full. (See Fig. 2.)

Although this is a recent example it is by no means unique. During 1921 I was engaged in the investigation of the effects produced by the action of $x$ rays on various conditions in which the effects of fibrous tissue formation were responsible for certain symptoms which failed to react to other physiotherapeutic remedies.* However grouped there was one outstanding feature in all the cases in this series-namely, the marked softening of excessive fibrous tissue by a comparatively short treatment with hard filtered $x$ rays. Clinical improvement was shown by such evidence as (1) the relief of pain when a nerve was being strangled by cicatrieial tissue in cases of superficial scars and in certain cases of neuromata in amputation stumps; (2) by greater and more rapidly secured freedom of movement in such a joint as the shoulder after prolonged suppuration and extensive operations in its neighbourhood; (3) by a greater range of action in cases of transplanted tendons for injuries of the musculo-spiral nerve; (4) by improvement in peripheral circulation where the brachial vessels were being constricted by scar tissue following gunshot wounds. Even in some cases of Dupuytren's contraction of long standing there was considerable softening of some of the lateral bands although the central
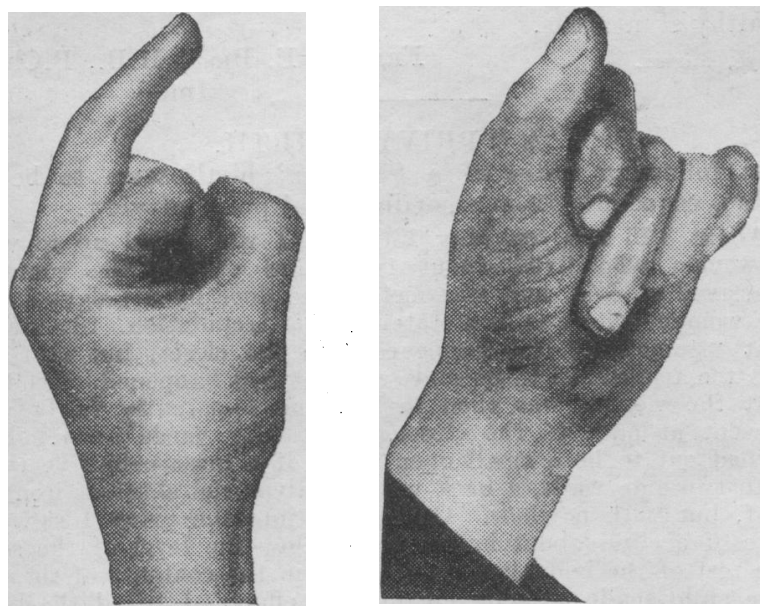

Fig. 1.-Before treatment.

FIG. 2.-After treatment.

palmar mass held out and so no clinical improvement resulted.

Although the majority of these observations were made on cases of war injury, a sufficient number of cases have been treated in civilian practice to prove that the same treatment is applicable. The action of radiotherapy which is now under consideration has been observed by others beside myself, but it does not appear to be at all widely known.

In post-operative radiotherapy of cases of amputation of the breast the softening effect on the scar tissue left after extensive dissection is so striking that its use for this purpose alone-apart, that is, from any prophylactic effect-would almost be justified.

As another example we may take the action of radiotherapy on keloidal tissue; it was in fact this action that first suggested to me the investigation on fibrous tissue generally. On consulting such references as came readily to hand $I$ discovered that radium treatment on scar tissue had been carried out by Dr. W. Stevenson of Dublin, and that the results had been published by him in two subsequent papers. $^{1}$ It is hardly necessary to point out that the only essential difference between radium therapy and $x$-ray therapy is in the wave-lengths employed in each case. Since radium is not so generally available as $x$-ray apparatus this reference to Stevenson's work confirmed me in my

* These results were published in the Archives of Radiology and Electrotherapy for August, 1921 . resolution to use intensive $x$-ray treatment. The formula resolved upon has not since been changed. It is 4 to $5 \mathrm{ma}$. through a 3 or $4 \mathrm{~mm}$. aluminium filter; Coolidge tube; spark-gap of 8 inches; 12 inches distance; time 12 minutes. Any attempt to cut down the dosage has led to disappointing results. No injurious results have ever been noticed.

It was not until a féw months ago that I accidentally discovered a short note by Dr. A. W. Williams on this same subject. $^{2}$ It appears that the attention of Dr. Williams was also drawn to this matter by the action of $x$ rays on keloidal tissue. The war injuries treated by him were more superficial, and his technique differed accordingly from that adopted by myself, but his published results were just as successful. Laquerrière (France) has reported two cases in which intensive radiotherapy, undertaken primarily for the treatment of uterine fibroids, resulted not only in a cure of this condition but also in marked freeing of intraabdominal adhesions, as shown by increased mobility of the uterus. $^{3}$ I do not, therefore, claim any originality in applying these methods of treatment, but the experience of others here mentioned emphasizes the fact that we have at our disposal a treatment which seems to hare great advantages over other methods.

So far I have been dealing with conditions which are similar inasmuch as we can group them as traumatic in origin. I should like to close by pointing out that other morbid conditions end in a fibrosis which is not always beneficial to the patient. Our nomenclature of diseases is too often purely topographical. Attention is distracted from the fact that such apparently disconnected affections as chronic arthritis, lumbago, pleurodynia, sciatica, and brachial neuritis, at any rate as regards their later stages, are in reality often the manifestations of that inflammation of the connective tissue known as "fibrositis." It matters little for our present purpose what the precise etiology of such cases may be provided that we realize that under the heading of "fibrositis" we are including all those cases in which the morbid process is essentially the inflammation of the white connective tissue, be the situation muscular, aponeurotic, synovial, or perineuritic. Whilst medicinal treatment or a masterly inactivity may effect a physical cure, functional restoration can only be obtained by local treatment. The numerous cases of relief of pain by treatment by $x$ rays in certain forms of sciatica and neuralgia may be explained by the softening action on various adhesive bands.

I believe that there is scope for radiotherapy in certain other diseases. I would quote especially two cases which have been treated, apparently successfully, by this method of treatment. The first was an instance of chronic mastitis in a male patient aged 17; the symptoms were greatly relieved after four treatments, although the condition had resisted other measures for nine months. The second case was one of obstinate empyema which had lasted for two years and had resisted all methods of treatment, including operation. Further surgical measures being considered inadvisable on account of the patient's general condition, radiotherapy was begun. The cavity was injected with bismuth emulsion, and that side of the thorax was treated twice weekly for a period of three or four weeks. Was it merely a coincidence that the condition began to improve and within a few weeks was healed and has remained so down to the present time? Is it not just as reasonable io suggest that collapse of the suppurating cavity has been helped by softening on the one hand the surrounding chronic fibrous tissue, and on the other the constricting bands which caused the double sausage pattern shown in the $x$-ray film of this case? I may be wrong in this contention, but $I$ would urge the trial of this method in a very similar condition, mechanically-namely, chronic bronchiectasis. Through the kindness of one of my colleagues $a$ trial is about to be made of this method and the results; if any, shall be brought to notice on some future occasion.

\section{REFERENCES.}

I British Mrdicat Jourival, Julỳ 4th, 1914, and Lancet, March 23rd,

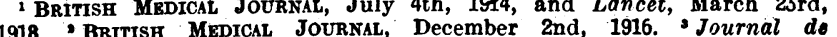
Radiologie et d'Electrologie, May, 192. 